\title{
Modelling of Aperture Coupled Microstrip Antenna Using Different Artificial Neural Network Techniques
}

\author{
Tanushree Bose Roy ${ }^{1}$, Jyoti Sah ${ }^{2}$, Meghna Datta ${ }^{3}$, Urvashree Borah $^{4}$ \\ Electronics and Communication Department, Sikkim Manipal University, Majhitar, Rangpo 1,2,3,4
}

\begin{abstract}
This paper presents the modelling of an aperture coupled microstrip antenna (ACMSA) using four different Artificial Neural Network (ANN) techniques, which are Back Propagation Network(BPN), Radial Basis Function Network(RBF),Generalized Regression Neural Network(GRNN) and a hybrid model which is a combination of Probabilistic Neural Network(PNN) and BPN. Firstly, these ANN models have been developed using MATLAB software, thereafter with the use of IE3D software, antenna design has been simulated, and validation performed, to check the accuracy of the developed models. Error percentages have been calculated, by comparing both the simulated and ANN models, for both normalized and un-normalized data sets. Thus the neural network approach eliminates the long, time-consuming process of finding various design parameters, using costly software packages.
\end{abstract}

Keywords: Aperture Coupled Microstrip Antenna (ACMSA), Artificial Neural Network (ANN), BPN, RBF, GRNN, PNN

\section{INTRODUCTION}

Most mobile wireless communication systems prefer using antennas that have a compact size and are low profile. This stems from the fact that to satisfy large volume and highspeed data transfer requirements, an antenna with high radiation efficiency is more desirable. A conventional ACMSA design was proposed by Pozar [1], which has most of these advantages, making them high performance printed antennas. In recent years, the art of using neural networks for wireless communication engineering [2] has become highly popular, as the basic purpose of applying $\mathrm{NN}$ is to change the lengthy analysis and design cycles required to develop high performance systems to very short product development time. The design of antenna becomes difficult, cumbersome and time-consuming, as the antenna parameters keep changing with time. Thus the use of NN helps solving the problem by eliminating the complex and time consuming mathematical procedures in designing of antennas [3].

Artificial Neural Networks(ANN) are non-linear information(signal) processing devices, which are built from interconnected elementary processing devices called neuron. The modification of synaptic weights is very much close to the procedure of linear adaptive filtering theory [4-5]. ANN can be implemented in electronic hardware or simulated in software. In the proposed work, the aim is to model an ACMSA using different ANN techniques. This work develops an ANN model, which gives all the parameters of an ACMSA for a desired frequency range, between $1.5 \mathrm{GHz}$ to $8.5 \mathrm{GHz}$. This particular range of frequencies is chosen for designing the model, as most of the usable frequencies lie within this range.

\section{AnTEnNa Design}

An Aperture Coupled Microstrip Antenna (ACMSA) [1415] consists of two substrates separated by a ground plane with a small aperture cut in the ground plane to allow coupling from open circuited microstrip feed line to the radiating patch [6-7]. Increase in substrate height greatly enhances bandwidth and resonant frequency which depends upon shape and dimension of radiating element $\left(L_{p}, W_{p}\right)$, dimensions of the ground plane $\left(L_{g}, W_{g}\right)$, shape and size of the aperture $\left(L_{a p}, W_{a p}\right)$, dimensions of feedline $\left(L_{f}, W_{f}\right)$, position of feedline $\left(X_{f}\right)$, and dielectric constants of the two substrates, as shown in Fig 1.

An aperture coupled antenna eliminates direct electrical connections between the feed conductor and radiating patch, and the ground plane electrically isolates the two structures. The two dielectric substrates can be selected independently to optimize both microstrip guided waves and patch radiating waves. Aperture coupled antennas are advantageous in arrays because they electrically isolate the feed and phase shifting circuitry from the patch antennas. The disadvantage is the required multilayer structure which increases fabrication complexity and cost.

\section{DEVELOPMENT OF ANN MODEL}

In the work, four ANN models are developed using Back Propagation Network (BPN) [5], Radial Basis Function Network (RBF) [5], Generalized Regression Neural Network (GRNN) [9] and a hybrid model using a combination of Probabilistic Neural Network (PNN) [5] and BPN. 


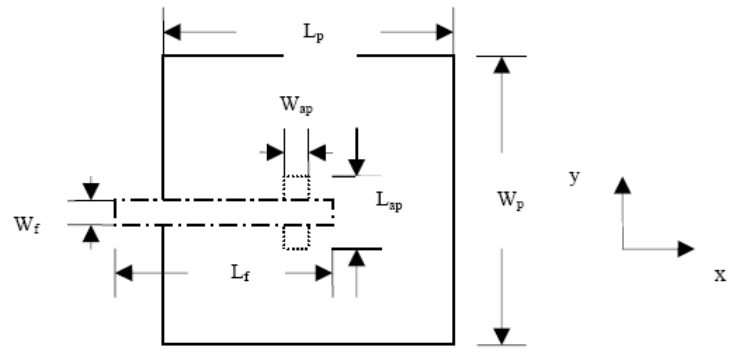

Fig. 1 Aperture Coupled Microstrip Antenna

Back propagation networks(BPN) are multilayered feed forward networks for training artificial neural network using extend gradient descent based on delta-learning rule [5], commonly known as back-propagation(of errors) rule.(Generalized delta rule). BPA provides an efficient method for changing the weights in a feedforward network. It minimizes the total squared error of the output computed by the net. The network is trained by supervised learning method.

Radial basis function (RBF) network is a feedforward network. It consists of input, hidden and output layers. It has only one hidden layer. Unlike BPN, this method is not based on the weight update rule, or the recursion technique, but on the curve-fitting technique.

Generalized Regression Neural Network (GRNN), as proposed by Donald F. Specht falls into the category of probabilistic neural networks. This neural network like other probabilistic neural networks needs only a fraction of the training samples a backpropagation neural network would need. The data available from measurements of an operating system is generally never enough for a backpropagation neural network. Therefore the use of a probabilistic neural network is especially advantageous due to its ability to converge to the underlying function of the data with only few training samples available.

Probabilistic Neural Network (PNN) is a multi layered feed forward network, with one input layer ,two hidden layers and one output layer. In its general form, it can be constructed after only a single pass of training exemplars, and two pass in the modified version, thus it is different from the feedforward network trained by the backpropagation algorithm. The activation function is derived from estimates of probability density function (PDF).

Each of these models were trained with 831 training patterns of input-output data, where resonant frequency $\left(f_{r}\right)$ is the input parameter, and the output parameters are $L_{g}, W_{g}, L_{a p}, W_{a p}, L_{p}, W_{p}, L_{f}, W_{f}, X_{f}$.

A neural network is created [13], consisting of an estimated number of layers, and of an estimated number of neurons in the layers. Initial synaptic weights and biases are set randomly[16].

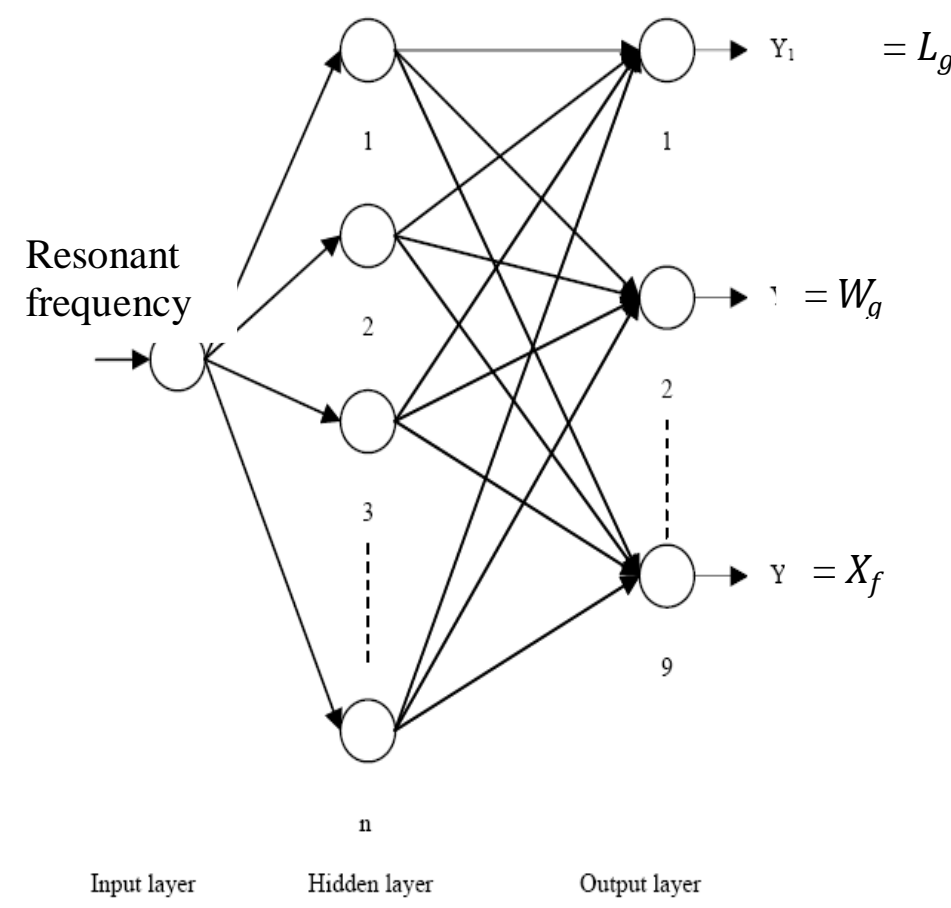

Fig. 2 Feed Forward Network

Fig 2 illustrates the structure of a simple feed forward network. The BPN and RBF model consists of one input layer, one hidden layer and nine output layers in the four developed models, while GRNN and PNN, unlike BPN and RBF, has two hidden layers.

After developing the model, the network is trained from the simulated data values and then, the testing is done for the values lying in the same range of resonant frequencies, but apart from the training set. Also, normalization of data is done using min-max method [12]

$$
I=I_{\min }+\frac{\left(I_{\max }-I_{\min }\right) \times\left(D-D_{\min }\right)}{\left(D_{\max }-D_{\min }\right)}
$$

where $I_{\max }$ and $I_{\min }$ are the $\mathrm{i} / \mathrm{p}$ range for the $\mathrm{n} / \mathrm{w}$ which is determined from the type of activation function for the ANN, which in our case is 0.1 and 0.9 respectively, $D_{\max }$ and $\mathrm{D}_{\min }$ indicates the maximum and minimum value associated.

Then, the verification of the model is done using IE3D software, where the resonant frequency of the ANN model is compared with that of the IE3D and the corresponding error percentage is calculated. The validation was performed for 10 random resonant frequencies ranging from $1.5 \mathrm{GHz}$ to $8.5 \mathrm{GHz}$. and the dielectric constant of both the substrates were taken to be 4.4.

\section{Training Algorithm for Hybrid Model}

Initially, the data set is classified using Probabilistic Neural Network (PNN) architecture, thereafter training on the output classes are done using Back Propagation Algorithm. The algorithm is discussed as:

STEP1: Create input unit STEP2: Initialize weights 
STEP3: For input unit ' $\mathrm{x}$ ', to be classified performs steps 4 to 6

STEP4: Calculate the Input unit [5].

STEP5: Calculate the summation units [5]

STEP6: Input units are classified to different classes as output units.

Each of these classes are trained using the Backpropagation Algorithm as proposed in STEP 7 to STEP 11.

STEP7: If stopping condition is false STEPS 8 to 11 is performed

STEP8: Computation of input, hidden and output layers in Back propagation architecture [5]

STEP9: Computation of error gradient

STEP10: Updation of weights and bias

STEP11: Test the stopping condition.

\section{RESUlTS AND DISCUSSION}

An ANN model for an Aperture Coupled Microstrip Antenna [10-11] was developed consisting of nine design parameters using BPN, RBF, GRNN and HYBRID (Using both BPN and PNN) networks. The simulated data collected from IE3D simulation software were used to train the above mentioned models with the use of MATLAB software. The models were trained as well as tested for both unnormalized and normalized data.The normalization was done using minmax method and the input output data was rescaled to the range $0.1-0.9$.

For the BPN model, the network had 1 hidden layer with 1800 neurons whose performance goal was $1 e^{-5}$ with 50000 epochs and learning rate was fixed at 0.05 . For 831 input/output training samples the time taken was $6 \mathrm{hrs}$ and the error was found to lie between $0 \%-5 \%$. While for the same input and output training samples, in case of RBF model the time taken was 4 secs and the error was found between $0 \%$ - 3.2\%.The GRNN model was developed using spread of 0.2 and the time taken was 6 secs and the error ranged from $0 \%-4.2 \%$. The HYBRID model which was developed using both BPN and PNN had the same parameters as in case of BPN model, it took $3 \mathrm{hrs}$ for 50000 epochs and the error was found to lie between 0$1.8 \%$..The error is calculated using the formula

$$
\text { Error } \%=\frac{\mid \text { Simulated Value }- \text { ANN Value } \mid}{\text { Simulated Value }} .100
$$

All the models were tested for 30 random frequencies. The input frequencies used in the ANN model were compared with the frequencies obtained from the IE3D software. The compared results along with the error percentages for each of the models are tabulated in TABLE 1, TABLE 2 ,TABLE 3 ,TABLE 4.To determine the most suitable model a comparative table, TABLE 5 , with the error rates and the mean error of all the models is presented .Also TABLE 6 shows the comparison between the resonant frequencies obtained from different methods

The mean error is given by

$$
\text { Mean }=\sum \text { error } / / 10
$$

A comparative study has been made on the normalized values for all the models which suggests that RBF was found to be the most efficient with error percentage ranging from $0 \%-6 \%$. However for other models the error was between $20 \%-40 \%$ which is highly unacceptable. Fig 8 represents the 2-D view of the radiation pattern showing as the azimuthal angle moves from $30^{\circ}-90^{\circ}$ the directivity increases. Also Fig. 11 shows that the current distribution is mostly at the edges of the feedline.

\section{Conclusion}

The recent surge of interest among communication engineers in applying neural network techniques as a tool of analysis or design, has opened many avenues for tackling the needs in wireless communications. High performance antennas are being developed to satisfy the competing demands of emerging wireless applications. The advantage of ANN is that it eliminates the repeated use of complex iterative processors. Also, in this work, the models have been designed in such a way, that all the design parameters of the ACMSA for any desired resonant frequency is obtained at a go.

\section{ACKNOWLEDGMENT}

The Authors would like to thank AICTE for sponsoring the project titled "Developing ANN Model for Multiband Printed Antennas using Hybrid Algorithm Technique" (Ref: No.: 8023/RID/RPS-31/(NER)2011-12) under whoch this work was carried out. We also acknowledge Electronics and Communication Department of Sikkm Manipal Institute of Technology,Majhitar and B.I.T., Mesra for its technical support to carry out this work. 
International Journal of Advanced Research in Computer and Communication Engineering Vol. 4, Issue 1, January 2015

\begin{tabular}{|l|c|c|c|c|c|c|c|c|c|c|c|c|}
\hline $\begin{array}{l}\text { Sl. } \\
\text { No }\end{array}$ & $\begin{array}{c}L_{g} \\
(\mathrm{~mm})\end{array}$ & $\begin{array}{c}W_{g} \\
(\mathrm{~mm})\end{array}$ & $\begin{array}{c}L_{a p} \\
(\mathrm{~mm})\end{array}$ & $\begin{array}{c}W_{a p} \\
(\mathrm{~mm})\end{array}$ & $\begin{array}{c}L_{p} \\
(\mathrm{~mm})\end{array}$ & $\begin{array}{c}W_{p} \\
(\mathrm{~mm})\end{array}$ & $\begin{array}{c}L_{f} \\
(\mathrm{~mm})\end{array}$ & $\begin{array}{c}W_{f} \\
(\mathrm{~mm})\end{array}$ & $\begin{array}{c}X_{f} \\
(\mathrm{~mm})\end{array}$ & $\begin{array}{l}\mathrm{f}_{\mathrm{r}} \\
(\mathrm{ANN})\end{array}$ & $\begin{array}{l}\mathrm{f}_{\mathrm{r}} \\
(\mathrm{IE} 3 \mathrm{D})\end{array}$ & $\begin{array}{l}\% \\
\text { error }\end{array}$ \\
\hline 1 & 40.355 & 41.603 & 0.8223 & 0.5246 & 19.955 & 20.091 & 22.592 & 4.0432 & - & 1.619 & 1.647 & 1.7 \\
\hline 2 & 24.954 & 24.949 & 1.4283 & 1.3168 & 5.0236 & 4.9148 & 14.190 & 3.0455 & - & 2.4 & 2.41 & 0.41 \\
\hline 3 & 14.036 & 13.944 & 2.998 & 3.347 & 5.1831 & 4.7772 & 4.4463 & 2.5696 & - & 3.9 & 3.84 & 1.56 \\
\hline 4 & 13.692 & 12.702 & 1.7327 & 0.8738 & 4.4087 & 4.2944 & 4.9656 & 2.1467 & - & 4.415 & 4.415 & 0 \\
\hline 5 & 10.338 & 9.0483 & 1.3549 & 1.8900 & 3.5852 & 5.0122 & 4.6164 & 2.8874 & - & 5.6 & 5.54 & 1.08 \\
\hline 6 & 6.7784 & 7.3910 & 1.8254 & 0.3175 & 5.3267 & 5.4265 & 4.9568 & 3.0879 & - & 6.72 & 6.72 & 0 \\
\hline 7 & 5.7674 & 6.1867 & 2.2606 & 0.0766 & 5.9736 & 3.4133 & 4.3209 & 4.5974 & - & 6.91 & 7.04 & 1.8 \\
\hline 8 & 6.2244 & 5.8002 & 2.5585 & 2.5146 & 4.5914 & 5.1753 & 4.7627 & 3.2006 & - & 7.27 & 6.91 & 5 \\
\hline 9 & 6.4996 & 5.5727 & 1.9716 & 0.7153 & 4.7074 & 6.6375 & 4.3391 & 2.3933 & - & 7.48 & 7.14 & 4 \\
\hline 10 & 4.7065 & 5.4139 & 1.4119 & 1.44 & 4.7593 & 4.9442 & 4.5935 & 2.7054 & - & 8.26 & 7.96 & 3.76 \\
\hline
\end{tabular}

TABLE I: Error Measurement For The Simulated Fr From Ie3d And The Nn Model Using Back Propagation Algorithm

\section{S.Parameters Display}

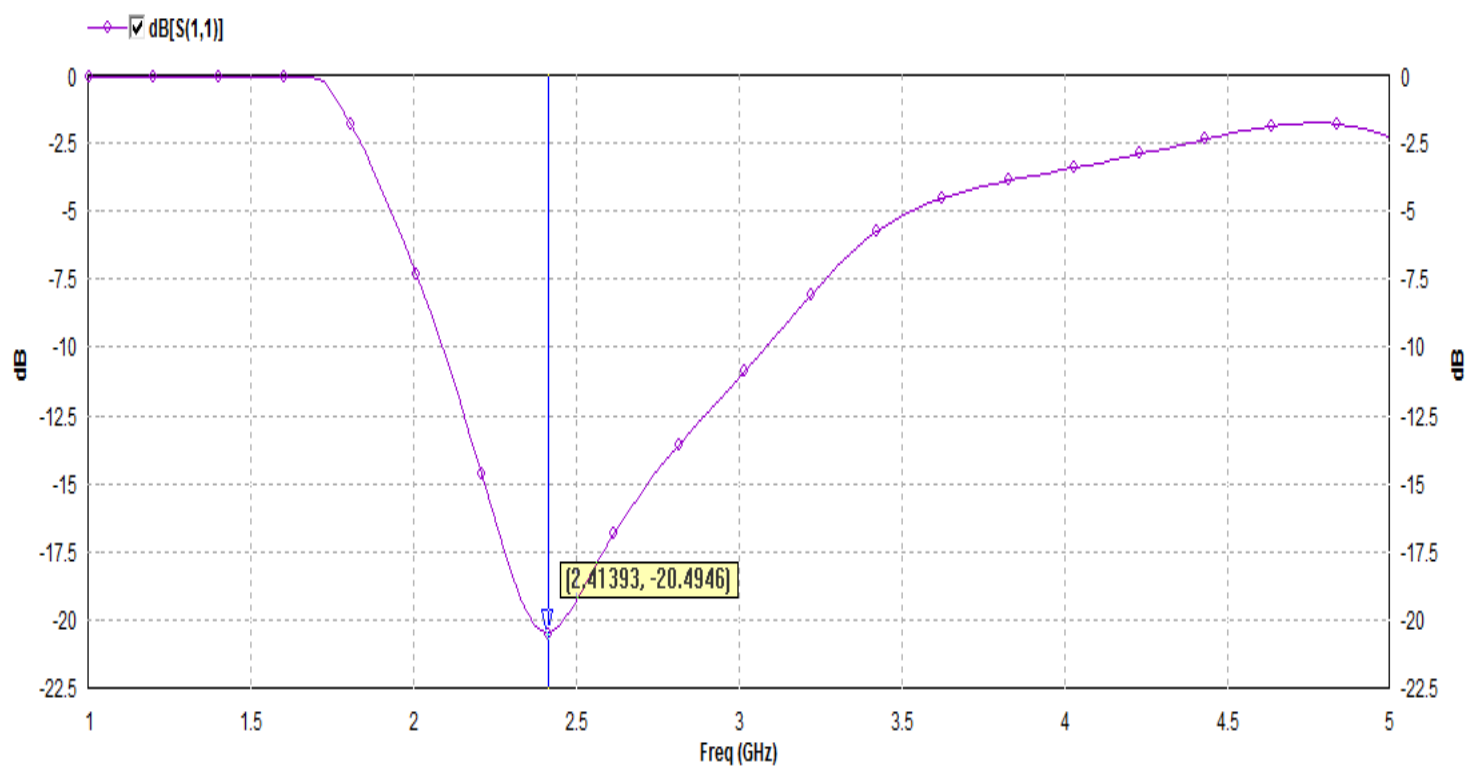

Fig. 3 The graph obtained from IE3D simulation for BPN model at $\mathrm{f}_{\mathrm{r}} 2.4$ 


\begin{tabular}{|c|c|c|c|c|c|c|c|c|c|c|c|c|}
\hline $\begin{array}{l}\text { Sl. } \\
\text { No }\end{array}$ & $\begin{array}{c}L_{g} \\
(\mathrm{~mm})\end{array}$ & $\begin{array}{c}W_{g} \\
(\mathrm{~mm})\end{array}$ & $\begin{array}{c}L_{a p} \\
(\mathrm{~mm})\end{array}$ & $\begin{array}{l}W_{a p} \\
(\mathrm{~mm})\end{array}$ & $\begin{array}{c}L_{p} \\
(\mathrm{~mm})\end{array}$ & $\begin{array}{c}W_{p} \\
(\mathrm{~mm})\end{array}$ & $\begin{array}{c}L_{f} \\
(\mathrm{~mm})\end{array}$ & $\begin{array}{c}W_{f} \\
(\mathrm{~mm})\end{array}$ & $\begin{array}{c}X_{f} \\
(\mathrm{~mm})\end{array}$ & $\begin{array}{l}f_{\mathrm{r}} \\
(\mathrm{ANN})\end{array}$ & $\begin{array}{l}f_{r} \\
\text { (IE3D) }\end{array}$ & $\begin{array}{l}\% \\
\text { error }\end{array}$ \\
\hline 1 & 40.440 & 40.440 & 1.5056 & 1.5056 & 16.253 & 16.253 & 20.875 & 3 & $\begin{array}{l} \\
8.2372\end{array}$ & 1.619 & 1.65 & 1.87 \\
\hline 2 & 24.824 & 24.824 & 1.5023 & 1.5023 & 5.0724 & 5.0724 & 14.977 & 3 & $\begin{array}{l}- \\
5.3040\end{array}$ & 2.4 & 2.41 & 0.41 \\
\hline 3 & 14.323 & 14.323 & 1.5018 & 1.5018 & 5.1199 & 5.1199 & 6.0545 & 3 & $\begin{array}{l}- \\
2.8309\end{array}$ & 3.9 & 3.83 & 1.82 \\
\hline 4 & 12.203 & 12.203 & 1.5022 & 1.5022 & 5.0479 & 5.0479 & 5.2408 & 3 & $\begin{array}{l}-5592 \\
\end{array}$ & 4.415 & 4.415 & 0 \\
\hline 5 & 8.8595 & 8.8595 & 1.5051 & 1.5051 & 4.9251 & 4.9251 & 5.0688 & 3 & $-\overline{2.5016}$ & 5.6 & 5.53 & 1.26 \\
\hline 6 & 6,8391 & 6.8391 & 1.4993 & 1.4993 & 4.9532 & 4.9532 & 4.9458 & 3 & $\begin{array}{l}- \\
2.4843\end{array}$ & 6.72 & 6.72 & 0 \\
\hline 7 & 6.6382 & 6.6382 & 1.5024 & 1.5024 & 4.9308 & 4.9308 & 5.0915 & 3 & $\begin{array}{l}- \\
2.5072\end{array}$ & 6.91 & 6.91 & 0 \\
\hline 8 & 6.1814 & 6.1814 & 1.5003 & 1.5003 & 5.0112 & 5.0112 & 4.9154 & 3 & $\begin{array}{l}- \\
2.4866\end{array}$ & 7.27 & 7.27 & 0 \\
\hline 9 & 5.9424 & 5.9424 & 1.4979 & 1.4979 & 4.9298 & 4.9298 & 5.0918 & 3 & $-\overline{2.5072}$ & 7.48 & 7.55 & 0.92 \\
\hline 10 & 5.0283 & 5.0283 & 1.1913 & 1.1913 & 4.7506 & 4.7506 & 5.2571 & 3 & $\begin{array}{l}-5138 \\
2.518\end{array}$ & 8.26 & 8.56 & 3.2 \\
\hline
\end{tabular}

\section{S-Parameters Display}

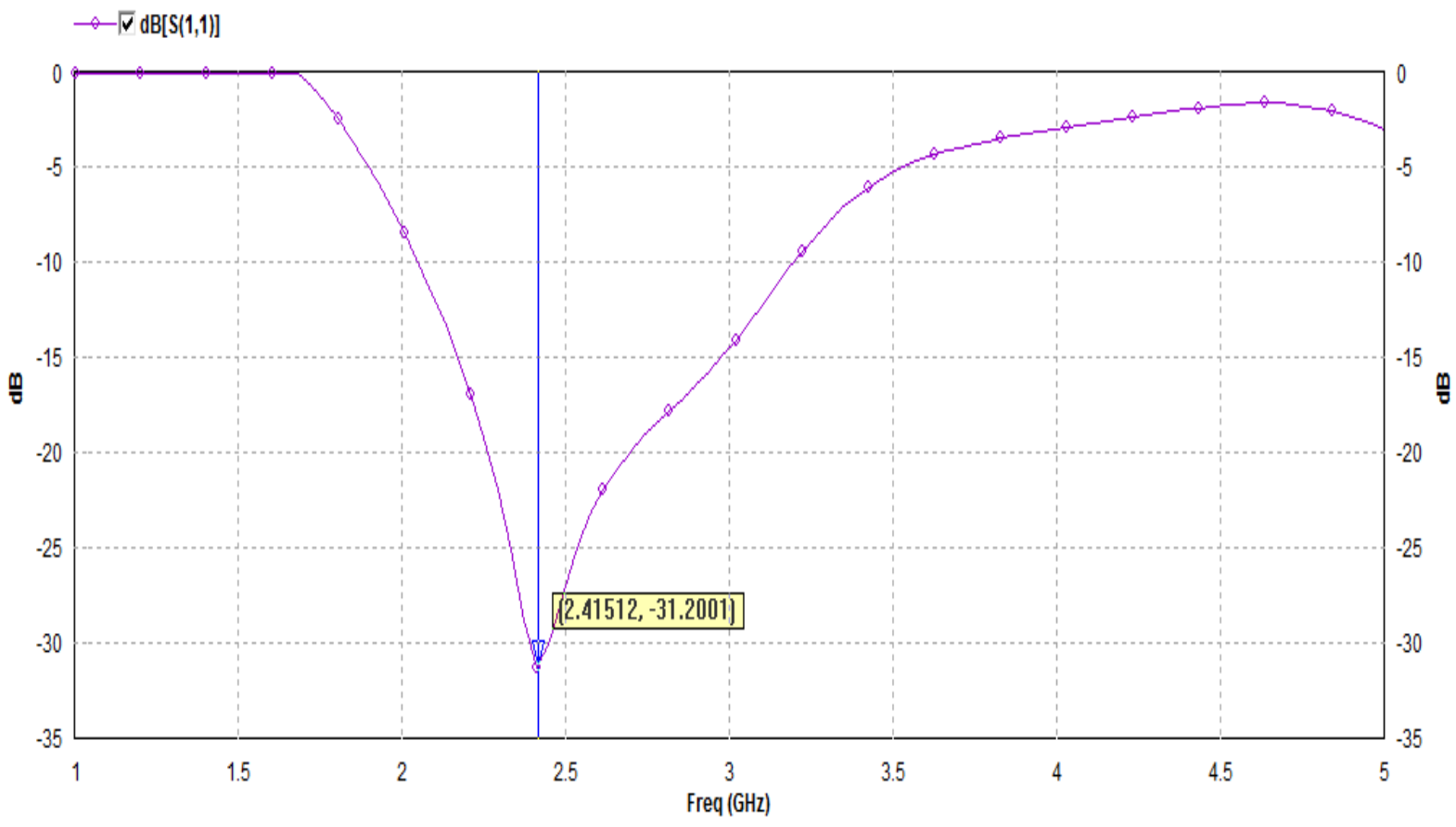

Fig. 4 The graph obtained from IE3D simulation for RBF model at $\mathrm{f}_{\mathrm{r}} 2$. 
TABLE III: Error Measurement For The Simulated Fr From Ie3d And The Nn Model Using Generalized Regression Neural Network

\begin{tabular}{|l|l|l|l|l|l|l|l|l|l|l|l|l|}
\hline $\begin{array}{l}\text { Sl. } \\
\text { No }\end{array}$ & $\begin{array}{c}L_{g} \\
(\mathrm{~mm})\end{array}$ & $\begin{array}{c}W_{g} \\
(\mathrm{~mm})\end{array}$ & $\begin{array}{l}L_{a p} \\
(\mathrm{~mm} \\
)\end{array}$ & $\begin{array}{l}W_{a p} \\
(\mathrm{~mm} \\
)\end{array}$ & $\begin{array}{c}L_{p} \\
(\mathrm{~mm})\end{array}$ & $\begin{array}{c}W_{p} \\
(\mathrm{~mm})\end{array}$ & $\begin{array}{c}L_{f} \\
(\mathrm{~mm})\end{array}$ & $\begin{array}{l}W_{f} \\
(\mathrm{~mm}\end{array}$ & $\begin{array}{c}X_{f} \\
(\mathrm{~mm})\end{array}$ & $\begin{array}{l}\mathrm{f}_{\mathrm{r}} \\
(\mathrm{ANN})\end{array}$ & $\begin{array}{l}\mathrm{f}_{\mathrm{r}} \\
(\mathrm{IE} 3 \mathrm{D})\end{array}$ & $\begin{array}{l}\% \\
\text { error }\end{array}$ \\
\hline 1 & 39.02 & 39.02 & $\begin{array}{l}1.49 \\
5\end{array}$ & $\begin{array}{l}1.49 \\
5\end{array}$ & 12.522 & 12.522 & 20.006 & 3 & - & 1.619 & 1.69 & 4.2 \\
\hline 2 & 25.149 & 25.149 & $\begin{array}{l}1.50 \\
1\end{array}$ & $\begin{array}{l}1.50 \\
1\end{array}$ & 5 & 5 & 15.427 & 3 & - & 2.4 & 2.4 & 0 \\
\hline 3 & 14.423 & 14.423 & $\begin{array}{l}1.50 \\
0\end{array}$ & $\begin{array}{l}1.50 \\
0\end{array}$ & 5 & 5 & 6.543 & 3 & - & 3.9 & 3.83 & 1.8 \\
\hline 4 & 12.211 & 12.211 & $\begin{array}{l}1.50 \\
2\end{array}$ & $\begin{array}{l}1.50 \\
2\end{array}$ & 5 & 5 & 5.0014 & 3 & - & 4.415 & 4.35 & 1.49 \\
\hline 5 & 8.873 & 8.873 & $\begin{array}{l}1.50 \\
5\end{array}$ & $\begin{array}{l}1.50 \\
5\end{array}$ & 5 & 5 & 5 & 3 & -2.5 & 5.6 & 5.6 & 0 \\
\hline 6 & 6.859 & 6.859 & $\begin{array}{l}1.50 \\
3\end{array}$ & $\begin{array}{l}1.50 \\
3\end{array}$ & 5 & 5 & 5 & 3 & -2.5 & 6.72 & 6.72 & 0 \\
\hline 7 & 6.624 & 6.624 & $\begin{array}{l}1.50 \\
3\end{array}$ & $\begin{array}{l}1.50 \\
3\end{array}$ & 5 & 5 & 5 & 3 & -2.5 & 6.91 & 5.76 & 2.21 \\
\hline 8 & 6.190 & 6.190 & $\begin{array}{l}1.50 \\
2\end{array}$ & $\begin{array}{l}1.50 \\
2\end{array}$ & 5 & 5 & 5 & 3 & -2.5 & 7.27 & 7.27 & 0 \\
\hline 9 & 5.947 & 5.947 & $\begin{array}{l}1.50 \\
1\end{array}$ & $\begin{array}{l}1.50 \\
1\end{array}$ & 5 & 5 & 5 & 3 & -2.5 & 7.48 & 7.51 & 0.3 \\
\hline
\end{tabular}

S-Parameters Display

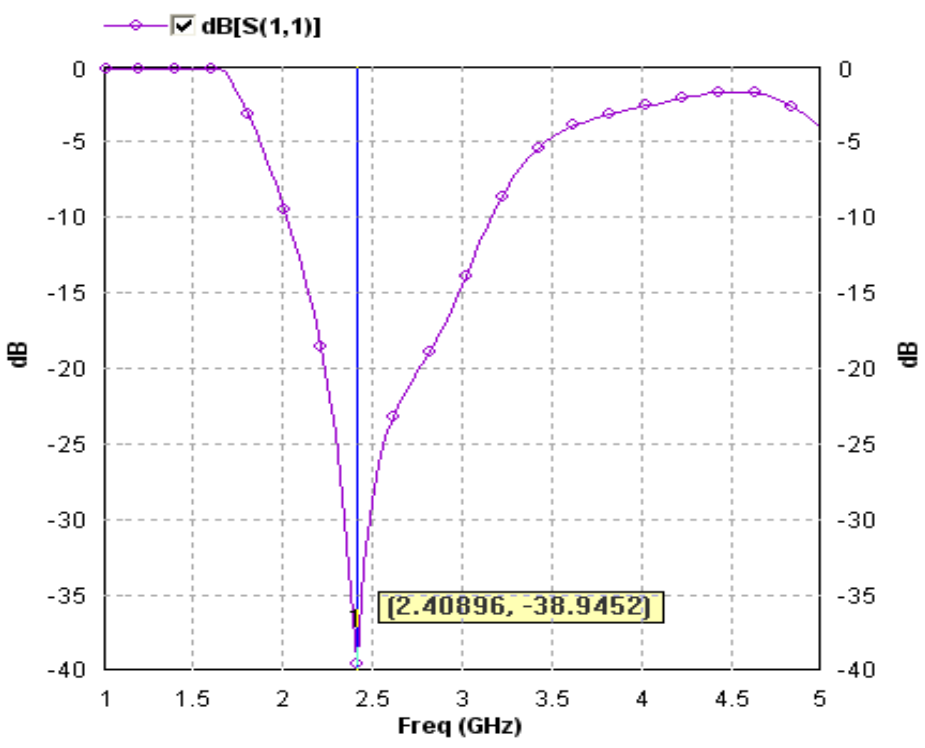


International Journal of Advanced Research in Computer and Communication Engineering

Vol. 4, Issue 1, January 2015

TABLE IV: Error Measurement For The Simulated Fr From Ie3d And The Nn Model Using Hybrid Network

\begin{tabular}{|l|l|l|l|l|l|l|l|l|l|l|l|l|}
\hline $\begin{array}{l}\text { Sl. } \\
\text { No }\end{array}$ & $\begin{array}{c}L_{g} \\
(\mathrm{~mm})\end{array}$ & $\begin{array}{c}W_{g} \\
(\mathrm{~mm})\end{array}$ & $\begin{array}{c}L_{a p} \\
(\mathrm{~mm})\end{array}$ & $\begin{array}{c}W_{a p} \\
(\mathrm{~mm})\end{array}$ & $\begin{array}{c}L_{p} \\
(\mathrm{~mm})\end{array}$ & $\begin{array}{c}W_{p} \\
(\mathrm{~mm})\end{array}$ & $\begin{array}{c}L_{f} \\
(\mathrm{~mm})\end{array}$ & $\begin{array}{c}W_{f} \\
(\mathrm{~mm})\end{array}$ & $\begin{array}{c}X_{f} \\
(\mathrm{~mm})\end{array}$ & $\begin{array}{l}\mathrm{f}_{\mathrm{r}} \\
(\mathrm{ANN})\end{array}$ & $\begin{array}{l}\mathrm{f}_{\mathrm{r}} \\
(\mathrm{IE} 3 \mathrm{D})\end{array}$ & $\begin{array}{l}\% \\
\text { error }\end{array}$ \\
\hline 1 & 40.499 & 40.501 & 1.480 & 1.495 & $\begin{array}{l}15.23 \\
8\end{array}$ & $\begin{array}{l}15.21 \\
8\end{array}$ & $\begin{array}{l}20.67 \\
9\end{array}$ & 3.004 & -8.028 & 1.619 & 1.63 & 0.67 \\
\hline 2 & 24.917 & 24.898 & 1.508 & 1.5 & 5.262 & 5.237 & $\begin{array}{l}15.69 \\
1\end{array}$ & 2.912 & -5.421 & 2.4 & 2.38 & 0.84 \\
\hline 3 & 14.370 & 14.392 & 1.498 & 1.505 & 4.885 & 4.906 & 6.802 & 2.999 & -3.003 & 3.9 & 3.83 & 1.8 \\
\hline 4 & 12.173 & 12.224 & 1.523 & 1.513 & 4.922 & 4.955 & 5.331 & 3.004 & -2.591 & 4.415 & 4.34 & 1.72 \\
\hline 5 & 8.835 & 8.827 & 1.513 & 1.510 & 5.049 & 5.039 & 4.828 & 3 & -2.455 & 5.6 & 5.6 & 0 \\
\hline 6 & 6.890 & 6.857 & 1.474 & 1.493 & 5.044 & 5.028 & 5.103 & 2.991 & -2.539 & 6.72 & 6.73 & 0.1 \\
\hline 7 & 6.627 & 6.599 & 1.472 & 1.491 & 5.031 & 5.020 & 5.109 & 2.991 & -2.540 & 6.91 & 6.91 & 0 \\
\hline 8 & 6.164 & 6.153 & 1.475 & 1.487 & 5.001 & 5.002 & 5.082 & 2.994 & -2.530 & 7.27 & 7.27 & 0 \\
\hline 9 & 5.912 & 5.915 & 1.482 & 1.485 & 4.981 & 4.989 & 5.046 & 2.997 & -2.516 & 7.48 & 7.5 & 0.2 \\
\hline 10 & 5.062 & 5.138 & 1.542 & 1.488 & 4.899 & 4.932 & 4.816 & 3.021 & -2.423 & 8.26 & 8.21 & 0.6 \\
\hline
\end{tabular}

\section{S.Parameters Display}

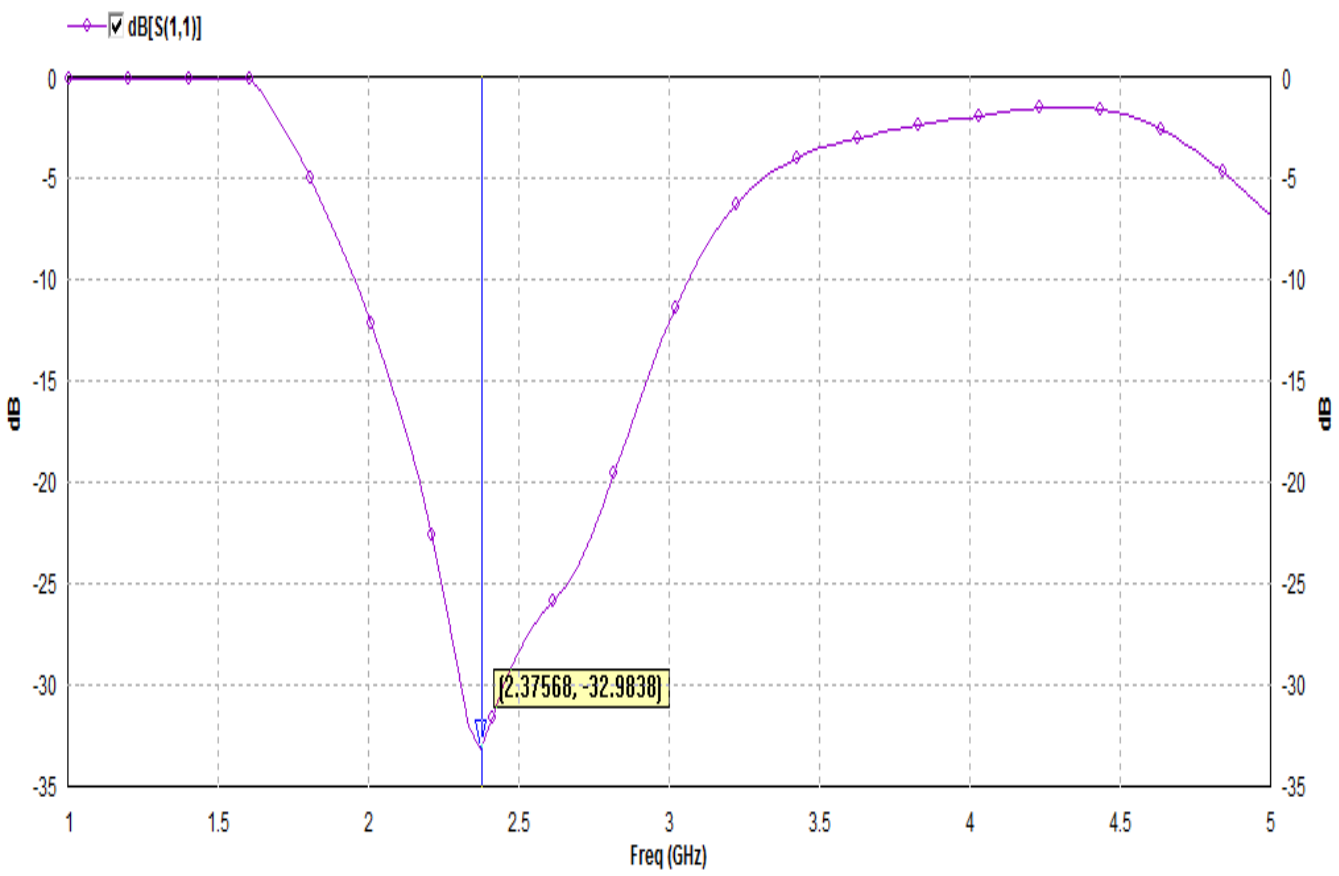


TABLE V: A Comparative Table Of The Error Rates And Mean Error Of All The Aforementioned Models

\begin{tabular}{|l|l|l|l|l|l|}
\hline & $\begin{array}{c}f_{r} \\
(\mathrm{ANN})\end{array}$ & $\begin{array}{l}\text { BPN } \\
\text { IE3D } \\
\% \text { error }\end{array}$ & $\begin{array}{l}\text { RBF vs } \\
\text { IE3D error }\end{array}$ & $\begin{array}{l}\text { GRNN vs } \\
\text { IE3D \% error }\end{array}$ & $\begin{array}{l}\text { HYBRID vs } \\
\text { IE3D } \\
\% \text { error }\end{array}$ \\
\hline 1 & 1.619 & 1.7 & 1.87 & 4 & 0.67 \\
\hline 2 & 2.4 & 0.41 & 0.41 & 0 & 0.84 \\
\hline 3 & 3.9 & 1.56 & 1.82 & 1.8 & 1.8 \\
\hline 4 & 4.415 & 0 & 0 & 1.49 & 1.72 \\
\hline 5 & 5.6 & 1.08 & 1.26 & 0 & 0 \\
\hline 6 & 6.72 & 0 & 0 & 0 & 0.1 \\
\hline 7 & 6.91 & 1.8 & 0 & 2.21 & 0 \\
\hline 8 & 7.27 & 5 & 0 & 0 & 0 \\
\hline 9 & 7.48 & 4 & 0.92 & 0.3 & 0.2 \\
\hline 10 & 8.26 & 3.76 & 3.2 & 0.72 & 0.6 \\
\hline ERROR & & 1.931 & 0.948 & 1.052 & 0.593 \\
\hline
\end{tabular}

TABLE VI: Comparison Showing Resonant Frequencies Obtained From Different Methods

\begin{tabular}{|c|c|c|cc|c|}
\hline SL NO & $\begin{array}{l}\text { Different ANN } \\
\text { techniques }\end{array}$ & $\begin{array}{l}\text { Resonant } \\
\text { frequency }\left(f_{r}\right) \text { obtained } \\
\text { from ANN model } \\
\text { obtained from IE3D } \\
\text { software }\end{array}$ & $\begin{array}{l}\text { Resonant frequency }\left(f_{r}\right) \\
\text { fromant frequency }\left(f_{r}\right) \\
\text { obtained from the } \\
\text { prototype antenna model }\end{array}$ \\
\hline 1 & BPN & 2.4 & 2.41 & 2.46 \\
\hline 2 & RBF & 2.4 & 2.41 & 2.46 \\
\hline 3 & GRNN & 2.4 & 2.4 & 2.46 \\
\hline 4 & HYBRID & 2.4 & 2.38 & 2.46 \\
\hline
\end{tabular}

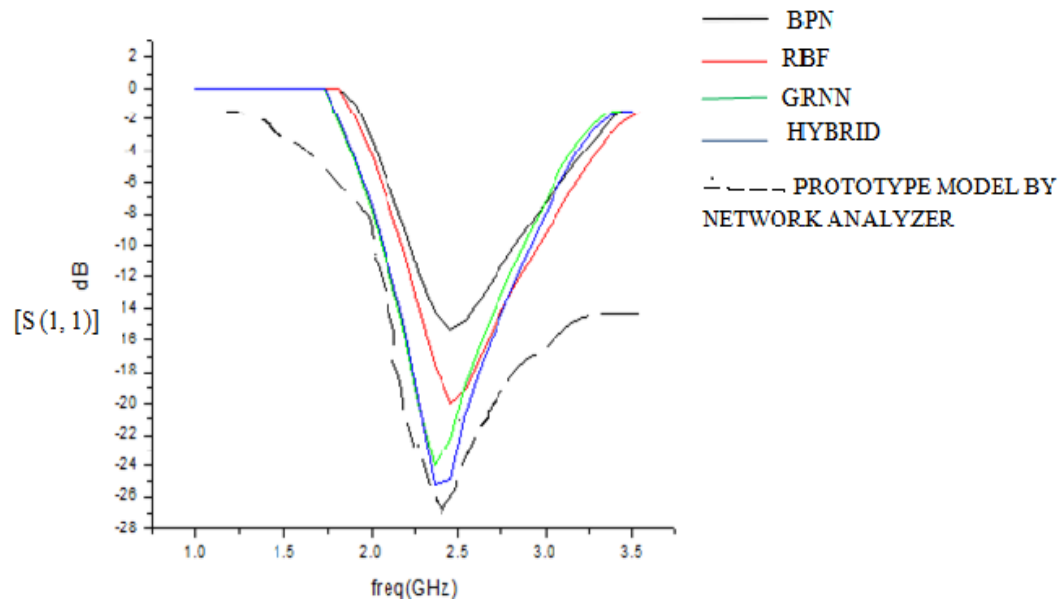

Fig. 7 Measured and simulated result of the designed antenna using Vector Network Analyzer and IE3D software simultaneously. 
International Journal of Advanced Research in Computer and Communication Engineering Vol. 4, Issue 1, January 2015

$$
\begin{aligned}
& \text { ○- } \mathrm{f}=1(\mathrm{GHz}), \mathrm{E} \text {-total, phi=30 (deg) } \\
& \mathrm{f}=1(\mathrm{GHz}), \mathrm{E}-\mathrm{total}, \mathrm{phi}=60 \text { (deg) } \\
& \longrightarrow-\Gamma \mathrm{f}=1(\mathrm{GHz}), \mathrm{E} \text {-total, phi=90 (deg) }
\end{aligned}
$$

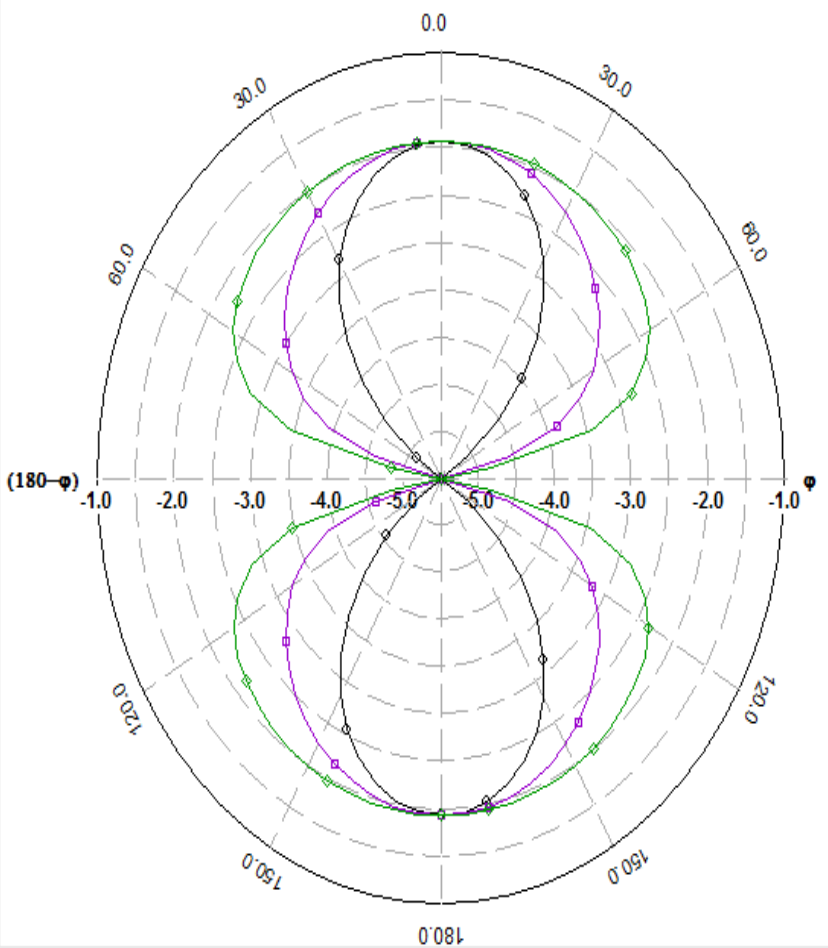

Fig. 8 Polar Plot

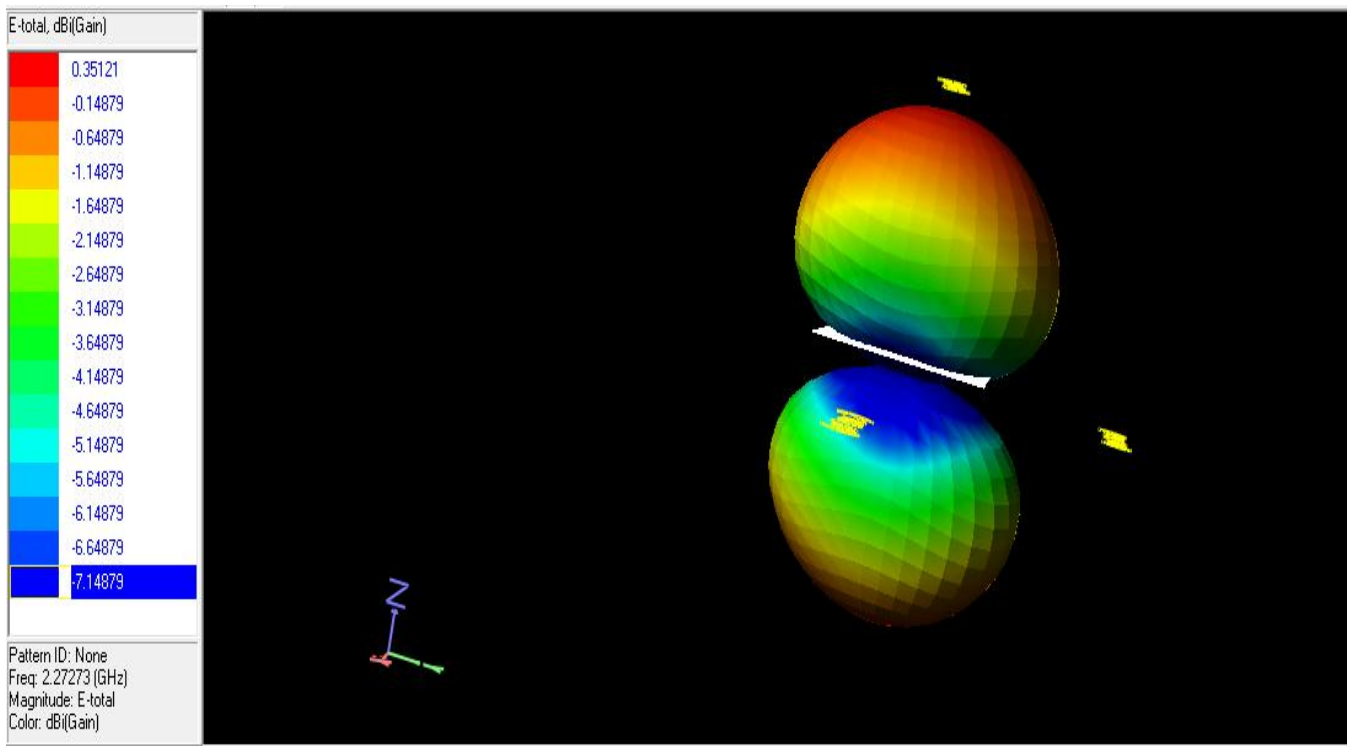




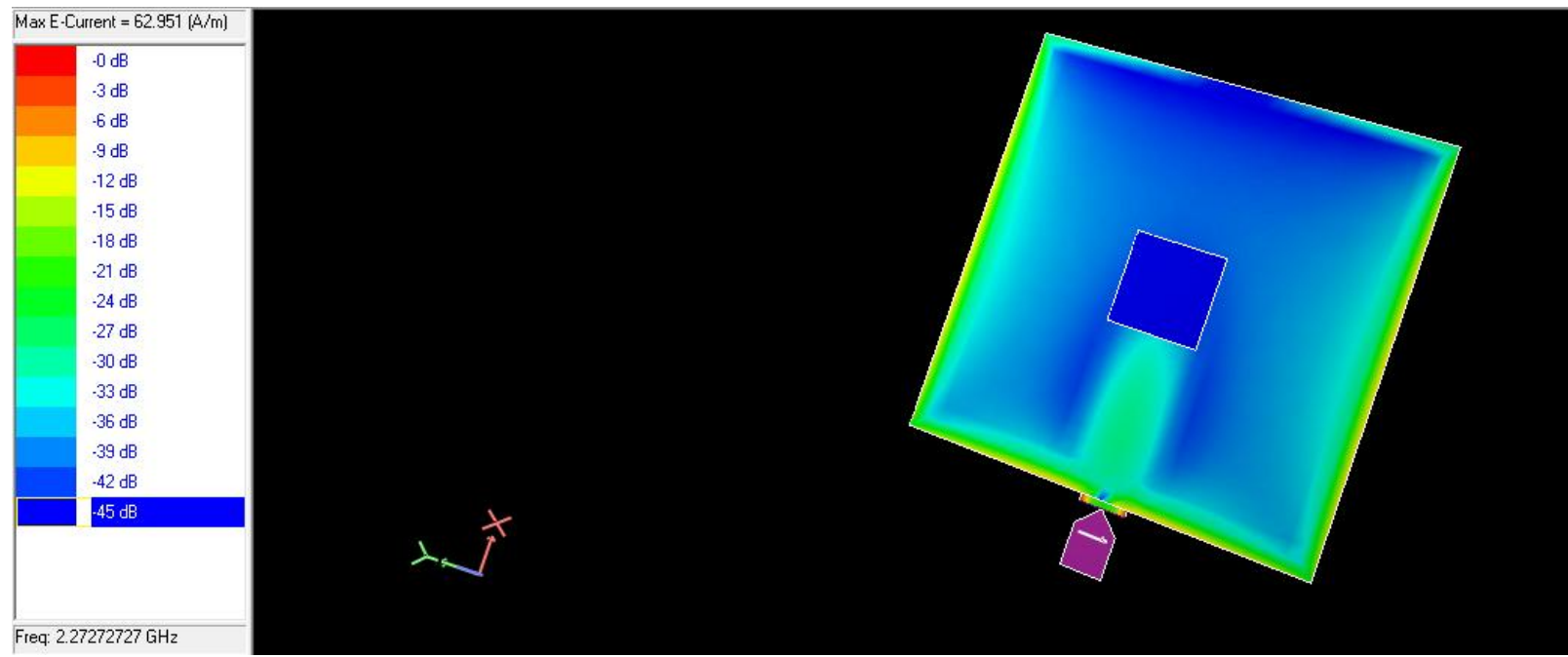

Fig. 10 Current Distribution with respect to the ground plane

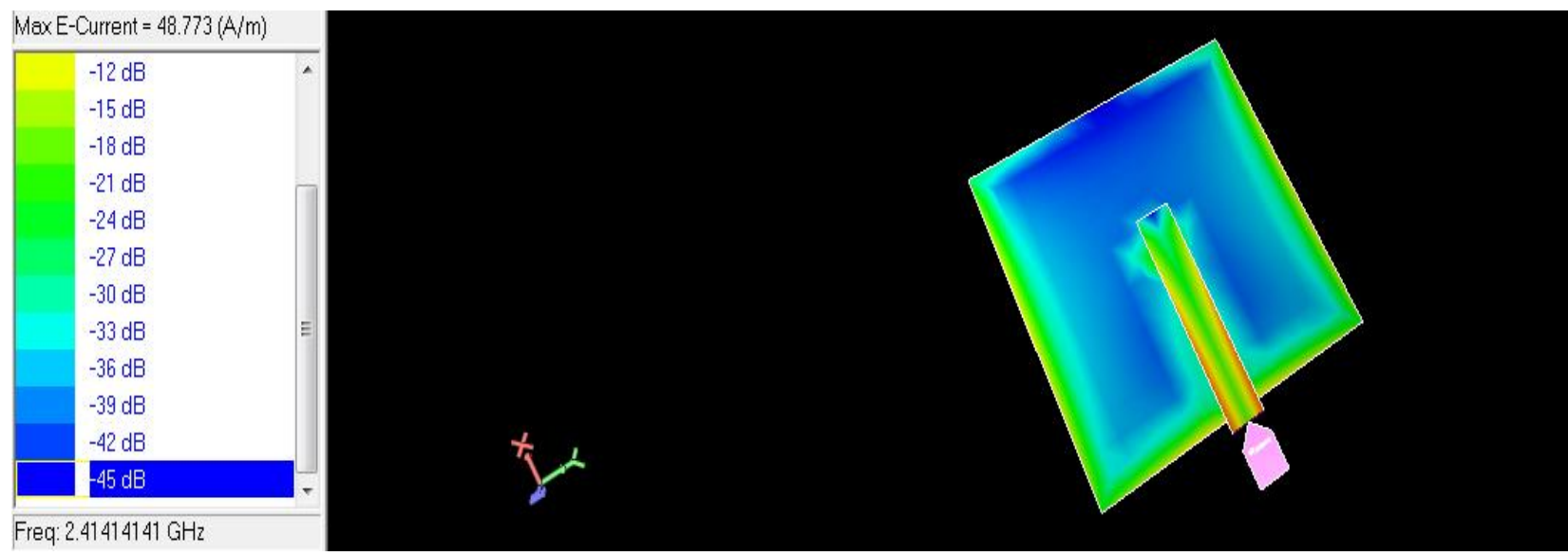

Fig. 11 Current Distribution with respect to the feed line

\section{REFERENCES}

[1] D. M. Pozar, "A Microstrip Antenna Aperture Coupled to a Microstrip Line", Electronics Letters, Vol. 21, pp.49-5O, January 17, 1985.

[2] A. Patnaik, D.E.Anagnostou, R.K.Mishra, C. G. Christodoulou, and J. C. Lyke, "Applications of Neural Networks in Wireless Communication”, IEEE Antennas and Propagation Magazine, Vol. 46, No. 3. June 2004, pp. 130-137

[3] A. Patnaik and R. K. Mishra, "ANN Techniques in Microwave Engineering", IEEE Microwave Magazine, March 2003, pp. 55-60.

[4] S. Haykin, "Neural Networks A Comprehensive Foundation",Pearson Education Pvt. Ltd., Singapore, 2004.

[5] S. N. Sivanandam, S. Sumathi and S. N. Deepa, "Introduction to Neural Networks using Matlab 6.0", Tata McGraw-Hill, New Delhi, 2006.
[6] T. Bose and N. Gupta, "Neural Network Model for Aperture Coupled Microstrip Antennas", Microwave Review,September 2008

[7] T. Bose and N. Gupta, "Design of Aperture Coupled Microstrip Antennas using Radial Basis Function Networks", Wireless Engineering and Technology,,September 2010.

[8] C. A. Balanis, "Antenna Theory Analysis and Design”,John Wiley \& Sons, Inc., New York, 2005.

[9] Donald F. Specht, "A General Regression Neural Network", IEEE Transactions on Neural Network, Vol.2. NO. 6, November 1991,pp.568- 576.

[10] P. L. Sullivian and D. H. Schaubert, "Analysis of an Aperture Coupled Microstrip Antenna", IEEE Transactions on Antenna propagation, Vol. AP-34, 1986, pp. 977-984. 
[11] A.Patnaik,D.Anagnostou andC.G.Christodoulou, "Neural Network in Antenna Engineering- Beyond Black Box Modelling",IEEE Transaction, 2005

[12] T.Jayalakshmi and Dr.A.Santhakumaran, "Statistical Normalization and Back Propagation for Classification", International Journal of Computer Theory and Engineering, Vol.3, No.1, February 2011, pp.1793-8201.

[13] N. Türker, F. Günes and T. Yildirim, "Artificial Neural Networks Applied to the Design of Microstrip Antennas", Microwave Review, June 2006. pp. $10-14$.

[14] P.Besso,D.Finouo,D.Forigo and P.Gianola, "Analysis of ApertureCoupled Multi-Layer Microstrip Antennas",Centro Studie Laboratori Telecomunicazioni, ITALI,1993,pp.1224-1227.

[15] Saed, M.A., "Efficient Method for Analysis and Design of Aperture Coupled Rectangular Microstrip Antenna," IEEE Trans. Antenna Propagation, Vol. AP-41, 1993, pp. 986-988.

[16] D. K. Neog, S.S.Patnaik, D.C.Panda, S.Devi, B.Khuntia and M. Dutta, "Design of Wideband Microstrip Antenna and the use of Artificial Neural Networks in Parameter Calculation", IEEE Antennas and Propagation Magazine, Vol. 47, No.3, June 2005, pp.60-65. 